\title{
Biometric-Based Authentication Model for E-Card Payment Technology
}

\author{
Peter Sungu Nyakomitta*, Vincent Omollo** \\ School of Computing and IT, Jomo Kenyatta University of Agriculture and Technology, P O Box 62000-00200 \\ Nairobi - KENYA
}

\begin{abstract}
The goals of this study were to develop and evaluate a model for acceptance of biometric-based access control for payment technologies used in commercial Banks. A wide diversity of systems requires reliable personal detection schemes to either authenticate or establish the identity of an entity requesting their services. The rationale of such schemes is to ensure that the rendered services are accessed only by a rightful user and no one else. In this paper, a biometric authentication system was modeled. This scheme eliminates the tension of cards which requires one to memorize theirs difficult passwords and pin numbers. The study centered on establishing how biometric authentication can be used in payment technology to boost e-card security. The target population included customers and DTB staff at Kisii branch. Simple random sampling technique was engaged to select respondents. The necessary data was collected using closed-ended questionnaires for easy of analysis. This data was then tabulated and presented in graphs for interpretation purposes. The researcher used the research study findings to design and develop a model, which was called BAECPT (Biometric-Based Authentication E-Card Payment Technology). The requirements for this model were obtained from the responses that the target population gave. Some research constructs loaded low than the theoretical established threshold values and was therefore dropped, while the ones that loaded higher than these values were retained. These are the ones that were included in the final model.
\end{abstract}

Keywords: BAECPT, E-Cards, Model, SEM.

Abbreviations: Diamond Trust Bank (DTB), TAM (Technology Acceptance Model), PIN (Personal Identification Number), ATM (Automatic Teller Machine), Structured Equation Modeling (SEM).

\section{Introduction}

Fingerprint authentication is a scheme which verifies a person's identity based on the fingerprints. This is based on the fact that every human being has unique fingerprints. Therefore, it is possible to create an automated identification program using fingerprints only. This requires that one must have provided fingerprints at an earlier point in time. Hence, fingerprint authentication systems rely on a database containing scans of fingerprints and the identities to which they are connected (Diane, 2014).

Authentication is the process of confirming the truth of an attribute of an entity (Jensen, 2009). It is is actually the act of verifying someone's identity. Three modes of authentication do exist. The first for, called first type authentication, involves accepting proof of identity given by a credible person who has first-hand evidence that the identity is genuine. The second type authentication is the comparison of the features of the objects themselves, to what is known about the objects of that origin. The third type authentication relies on documentations or other external affirmations. The researchers adopted the second type of authentication.

Credit cards, debit cards and prepaid cards are the most common forms of electronic payments. These E-cads require that the consumer or the business use a plastic card, commonly with a magnetic stripe. The card holder gives his card or card number to a merchant who swipes the card through a terminal or enters the data to a computer system. The terminal transmits data to his bank, the acquirer. The acquirer transmits the data through a card association to the card issuer who makes a decision on the transaction and relays it back to the merchant, who gives goods or services to the card-holder. Funds flow later for settlement with credit cards and are debited immediately for debit or pre-paid cards (AdMonsters, 2013).

Signaling theory is important in describing behavior when two entities (clients and organizations) have access to different information. The sender (organization) must choose whether and how to communicate (signal) that information. The receiver (client) must also choose how to interpret that signal (Connelly, 2011). According to (Dainelli, 2011), signaling theory speculates that most profitable companies provide the market with more and better information.

The intent of this paper was to develop a model for the incorporation of fingerprint technology, which is a form of biometric-based authentication, with the electronic card payment technology. Previously, fingerprint recognition has been used in access control to rooms and in criminology to identify the culprits. The number of cards that customers carry around for different purposes have become immense. This is coupled with the burden of remembering their Personal Identification Number (PIN). Moreover, if someone gets access to the PIN of a 
smart card, then he can use the same for financial fraud such shopping and illicit cash withdrawals. Biometricbased authentication can easily curb this as the fingerprint technology can never be identical for more than one person. Therefore, the researchers sought to investigate the possibility of registering these cards in the database and afterwards, instead of using PINS, fingerprint technology can be used to authenticate their owners. This means that one does not need to carry his cards around and recall their passwords. The idea is making payments by the press of a fingerprint sensor, in a way similar to the one used for building access control. Once the fingerprint sensor is pressed, all the customer details should be displayed in a terminal and afterwards, all his transactions can be concluded. This technology can then be extended to authenticate bank customers to Automated Teller Machines (ATMs).

\section{Methodology}

This section describes how the research was designed, the target population, how the sample and sampling procedures were carried out, the various data collection mechanisms, how data was processed and analyzed. Finally, it gives the procedure adopted to develop the BAECPT model.

The research design adopted was a mixture of a survey and experimentations, which aided to achieve the study objectives, with a target population being customers and staff of DTB Kisii branch. Simple random sampling method was employed to select respondents. This was deemed appropriate in provision of representative data. Data was collected using questionnaires that were distributed to the respondents so as to get the required data for this study. The obtained data was then tabulated, categorized and exposed to appropriate statistical computations as discussed in the sub-sections below.

The Lisrel (linear structural relations) software was employed to develop the proposed model. This is statistical software package used in structural equation modeling, which is a technique for testing and estimating causal relations using a combination of statistical data and qualitative causal assumptions.

Structural equation models permitted the researchers to run both confirmatory and exploratory modeling. This implies that these two are suitable for both theory testing and theory development. Confirmatory modeling normally starts out with a hypothesis that gets represented in a causal model. The hypothesized model was tested against the obtained measurement data to determine how well the model fitted the data.

\section{Sample Population}

A total of twenty respondents were chosen randomly to take part in the study as shown in Table 1 below.

\begin{tabular}{|l|l|}
\hline Population Type & Number \\
\hline Managers & 3 \\
\hline Staff & 5 \\
\hline Customers & 12 \\
\hline Total & $\mathbf{2 0}$ \\
\hline
\end{tabular}

Table 1: Sample Population

\section{Questionnaire Design}

The questionnaire that the researcher used consisted of four sections: Demographic Data; Biometricbased Authentication; E-Card payment Technology; and the signaling theory \& TAM sub-sections. The respondents were required to tick their preferred choice from a list of options that were provided in each section.

\section{Hypothesized Model}

Signaling theory (ST) was used in conjunction with the Technology Acceptance Model (TAM) to develop the proposed BAECPT model. Figure 1 below shows the proposed extended TAM that was enhanced by use of the variables obtained from the signaling theorem. 




Robustness is the ability of a system to resist change without adapting is initial stable configurations (Wallenburg, 2012). Acceptability refers to the property of a system being socially sound or within the realm of what is appropriate. Availability refers to the degree to which a system is in a specified operable and committable state at the start of the mission, when the mission is called for at an unknown time. Distinctiveness refers to the quality of a system to be recognizable and different from other systems. Accessibility is the degree to which system is available to as many people as possible (Bridget, 2011).

\section{Reliability Of The Questionnaire}

\section{Results And Discussion}

According to Elizabeth (2012), reliability is the extent to which results are dependable over a specific period of time. A research instrument is reliable if it gives the same results every time (Martin, 2014). The various variables of the study were examined for reliability using Cronbach's Alpha and the results are as presented in Table 1 below.

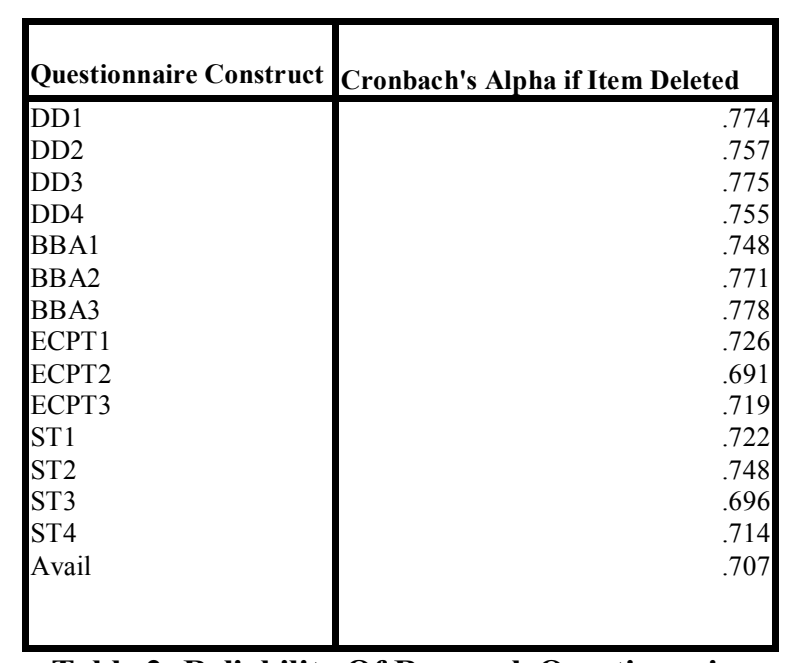

Table 2: Reliability Of Research Questionnaire

This table shows that all the questionnaire constructs loaded higher than the threshold value of 0.7 (Elizabeth, 2012) except variables ECPT2 and ST3. This means that the questionnaire that the researcher used can be relied upon.

\section{Convergent and Discriminant Validity Of the Research constructs}

Variable validity determines whether the research actually measures that which it was intended to measure (Mohammed, 2013). Factor Analysis is used to find thriftiness among several variables. The expedition is usually for underlying factors that each explains the variation among several variables. In this paper, this analysis was used to study both convergent and discriminant validity. Principal Component Analysis was used with Varimax Kaiser Normalization as it considers all the available variance. Convergent validity 
refers to the degree to which items that measure the same construct are correlated. Discriminant validity tests whether the concepts or measurements that are supposed to be unrelated are, in fact, unrelated.

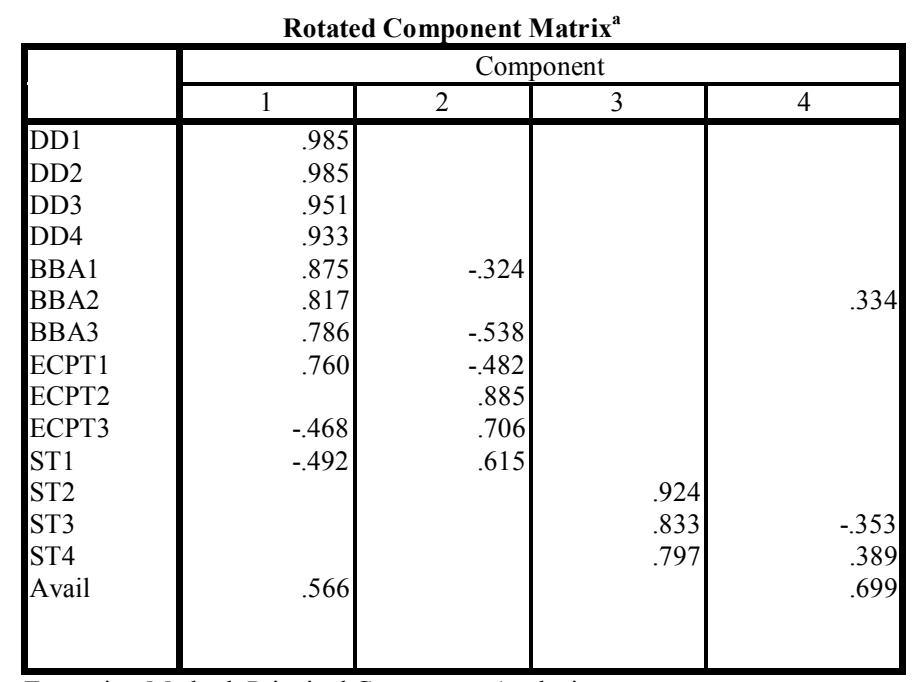

Extraction Method: Principal Component Analysis.

Rotation Method: Varimax with Kaiser Normalization.

a. Rotation converged in 9 iterations.

Table 5: Component Factor Loading On BAECPT Model Adoption

The cutoff value for both convergent and discriminant validity is 0.5 (Elizabeth 2012). Table 5 shows that most questionnaire constructs loaded higher than this value except ECPT3 and ST1. Hence both discriminant and convergent validity were achieved.

\section{Model Development}

Programs such as LISREL make it possible to combine structural equation modeling and confirmatory factor analysis. Any Lisrel model is about approximating the observed correlation (covariance) matrix (Ganzeboom, 2010). Therefore Lisrel was used in this research paper. The figure below shows the hypothesized path diagram.

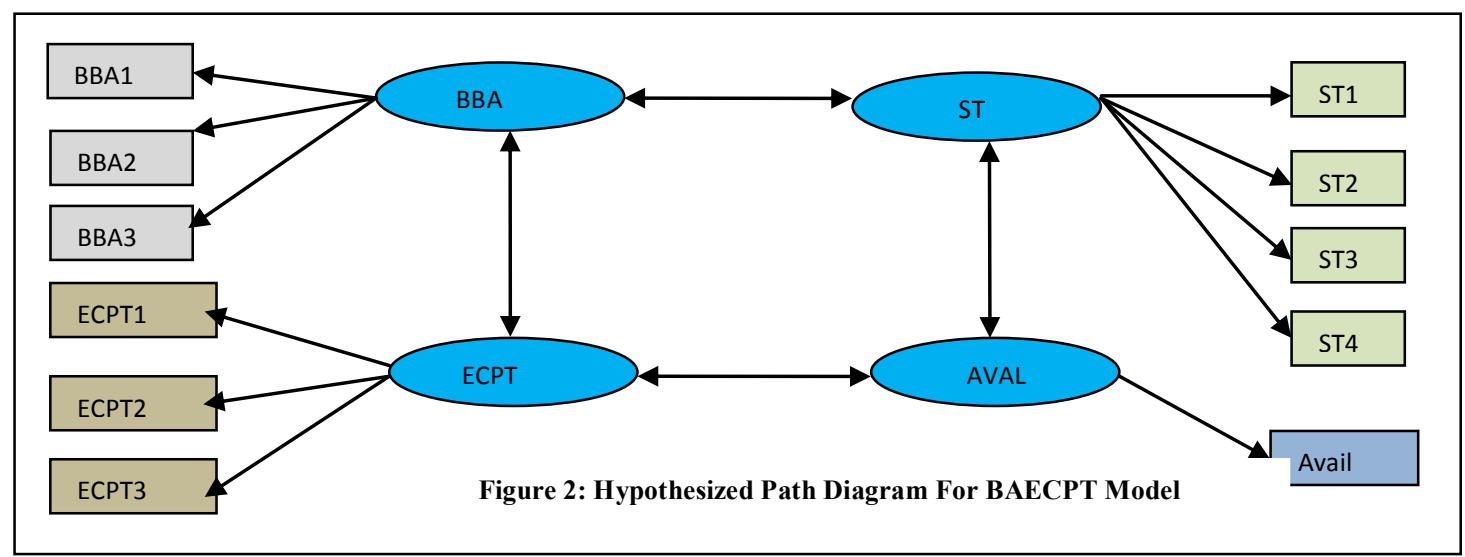

The latent variable Biometric -Based Authentication $(B B A)$ was measured using constructs $B B A 1$ to $B B A 3$, while the latent variable E-Card Payment Technology (ECPT) was measured using constructs ECPT1 to ECPT3. Latent variable Signaling Theory (ST) was measured with constructs ST1 to ST4 while Technology Acceptance Model was determined using construct Avail.

The researcher used Lisrel software to model the hypothesized BAECPT path shown in Figure 2. The results obtained are shown in Figure 3 below. 


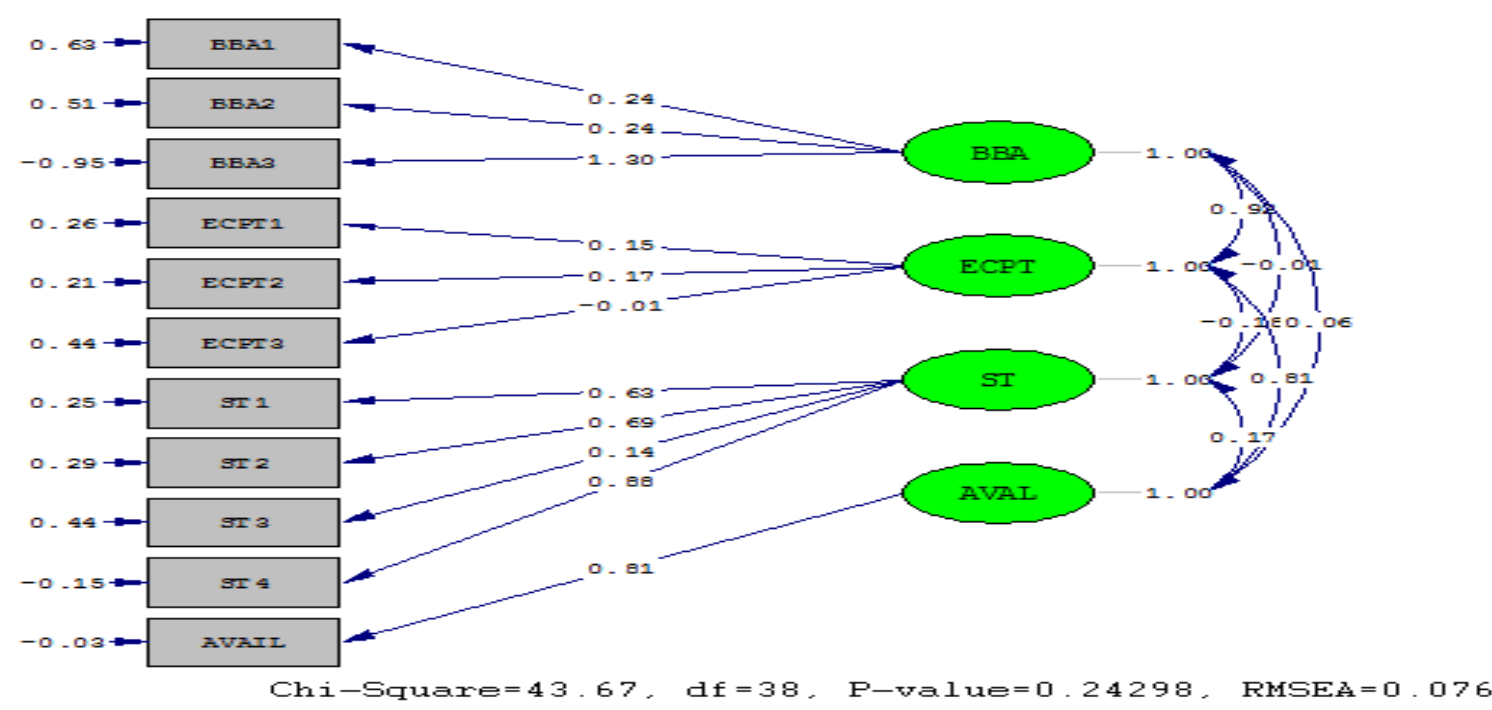

Figure 3: A Path Diagram Presentation Of BAECPT Model

The threshold value for the path costs is 0.05 (Gerhard, 2010). From Figure 3 above, all the path costs, apart from that one for construct $E C P T 3$, were sufficiently above this value. This path was therefore removed to come up with the final $B E C P T$ model as shown in Figure 4 below.

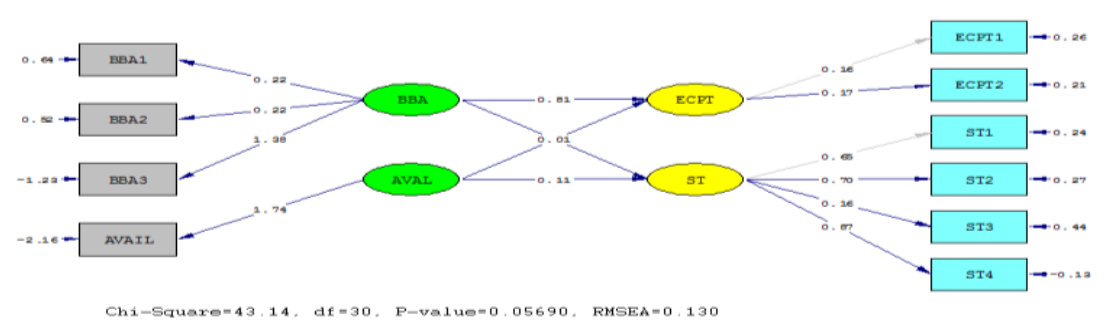

Figure 4: Final BECPT Model

\section{Model Evaluation}

The researchers sought to establish the fit of an model above. This was done with the intention of determining how well it models the data. This is a fundamental exercise in Structured Equation Modeling. It provides the basis for acceptance or rejection of the models. The output of the Lisrel program included matrices of the estimated relationships between variables in the model. An evaluation of fit basically determines how similar the predicted data are to matrices containing the relationships in the actual data.

Regression analysis was employed in this paper to determine how well the developed model fits into real world data. Specifically, the standardized factor loading squared $\left(\mathrm{R}^{2}\right)$ was used. It measures the extent that a factor can explain the variance in a manifest variable. R2 is the amount of disparity in the dependent variable that is accounted for by discrepancy in the independent variables. It is calculated by the significance of the coefficient of determination, often called R2 adjusted. This is because R square tends to over-approximate the accomplishment of the model when applied to the actual world. Therefore an Adjusted R Square value is considered which accounts for the number of variables in the model and the number of observations a model is based on. Figure 5 below shows the obtained results. 


\begin{tabular}{||c|c|r|r|r|}
\hline \multicolumn{6}{|c|}{ Model Summary } \\
\hline Model & \multicolumn{1}{|c|}{ R } & R Square & $\begin{array}{c}\text { Adjusted R } \\
\text { Square }\end{array}$ & $\begin{array}{c}\text { Std. Error of } \\
\text { the Estimate }\end{array}$ \\
\hline 1 & $.946^{\text {a }}$ & .894 & .874 & .285 \\
\hline \multicolumn{3}{|c|}{ a. Predictors: (Constant), Acceptability, Accessbility, } \\
Availability, Distinctiveness \\
\hline \multicolumn{4}{|c|}{} \\
\hline
\end{tabular}

Figure 5: Model Evaluation

The value of Adjusted R square that is closer to 1 is recommended. In Figure 5, the value of adjusted $\mathrm{R} 2$ is .843, which is closer to 1 . Hence the model sufficiently accounts for the real world data.

\section{Comparison With Other Models}

Technology acceptance models attempt to explain the adoption of information systems. Some of the most common models include the Technology Acceptance Model (TAM), Technology Acceptance Model 2(TAM2), Combined TAM and TPB(C-TAM-TPB), and The Unified Theory of Acceptance and Use of Technology (UTAUT) (Chuttur, 2009) as shown below.

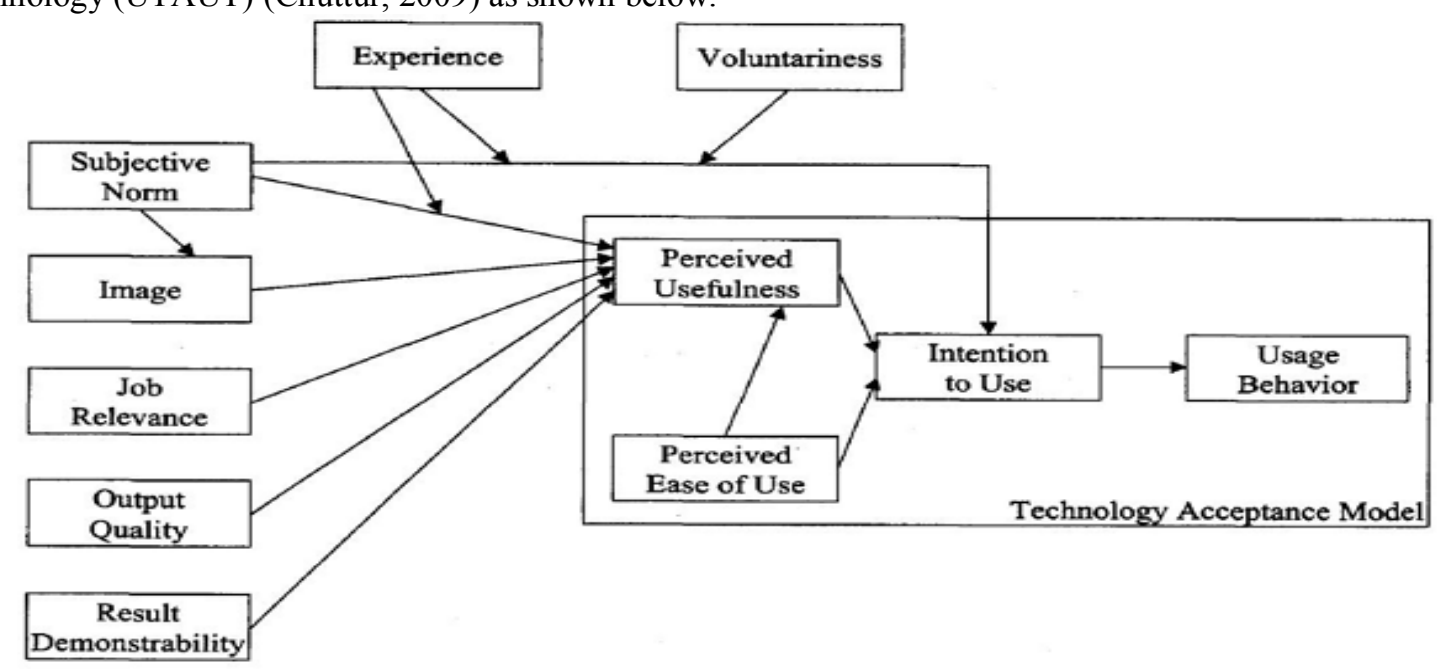

Figure 6: Technology Acceptance Model 2

The Technology Acceptance Model 2 explains perceived usefulness and usage intentions in terms of social influence and cognitive instrumental processes. Its weakness is that it concentrates on social influence and cognitive instrumental processes, leaving other influences such as availability, robustness, accessibility, acceptability and distinctiveness. 


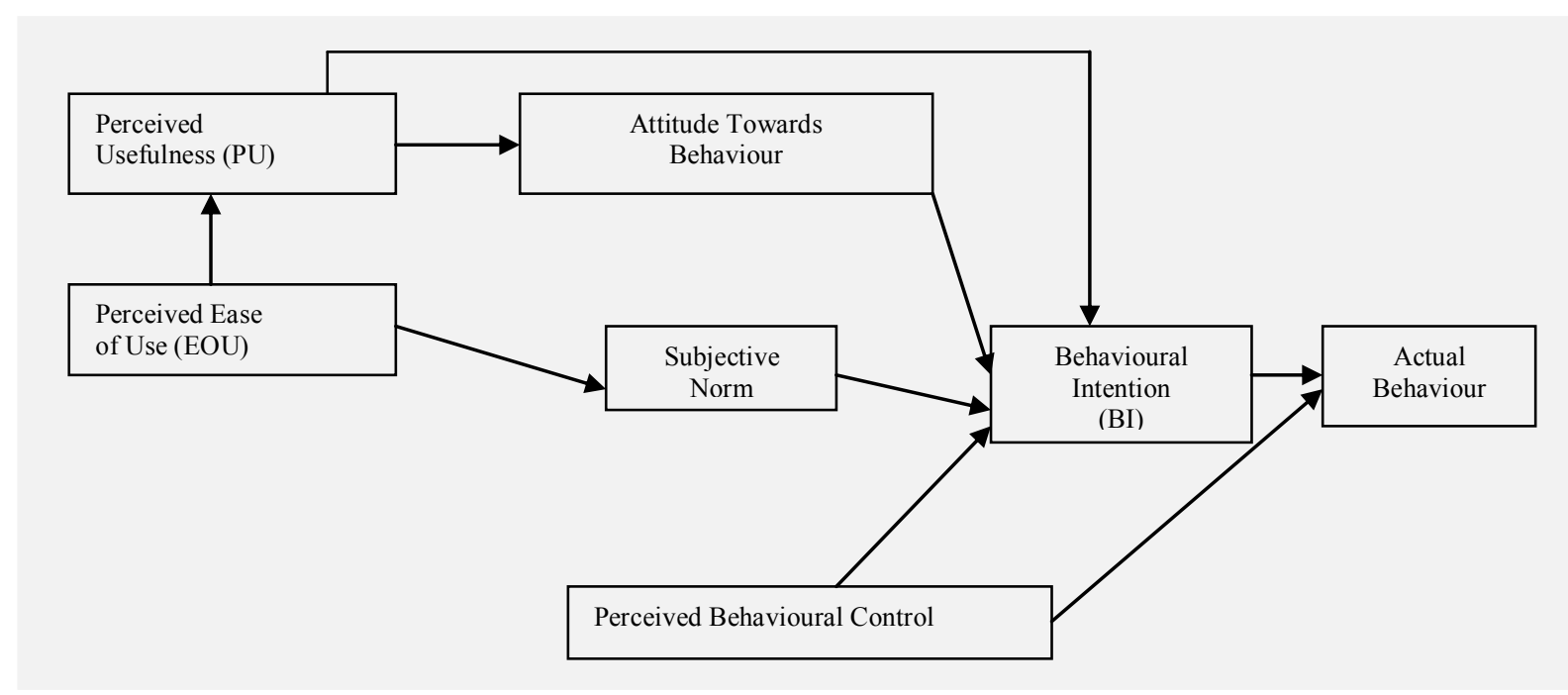

The combined TAM and TPB included the influence of social and control factors on behavior (from the Theory Of Planned Behavior). This was meant to enable it provide a more exhaustive test of the important determinants of Information Technology utilization. However this concentrated mostly on behavior of the users, leaving out the features of the information systems themselves.

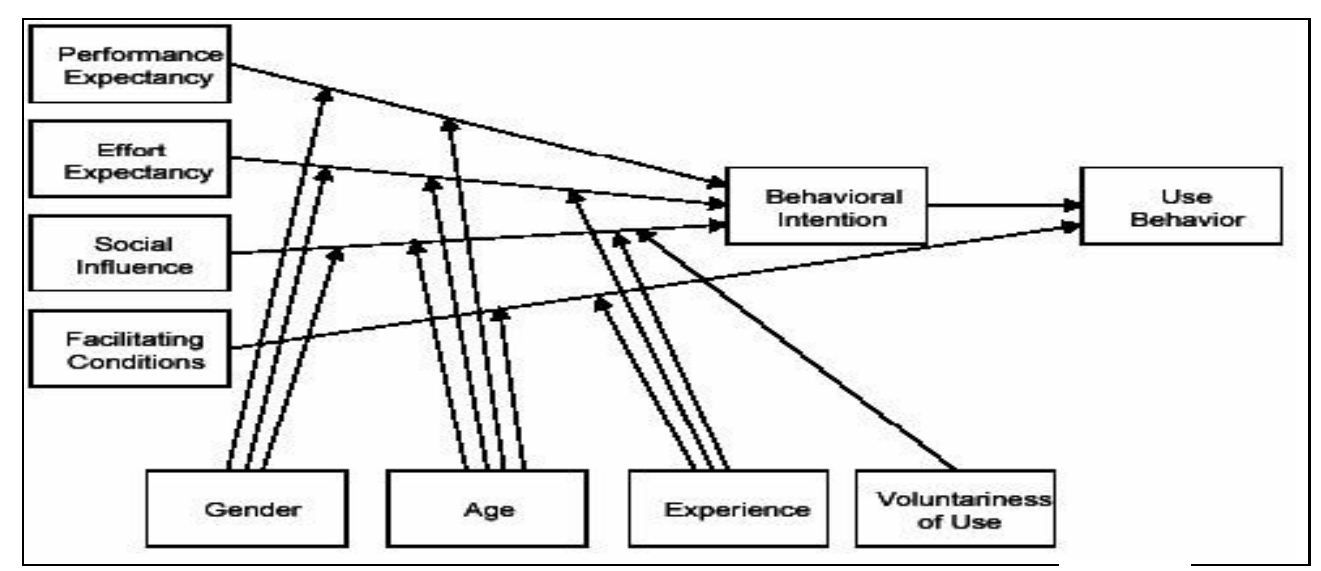

Figure 8: Unified Model of Acceptance and Use of Technology(UMAUT)

$U M A U T$ is an acceptance and adoption model that studies common people's adoption decision and innovation behaviors. It can be suitable in corporate environments in determining the degree of staff and customers motivation when adopting new software or technology. Unfortunately, it fails to take into account the characteristics of the system itself that may influence its adoption.

Comparing the developed model with these models, it was clear that our model provided an ideal explanation on the factors that make staff and customers adopt the finger-print authentication (form of biometric -based authentication) for their electronic cards. The added constructs, availability, robustness, accessibility, acceptability and distinctiveness are the qualities of the systems themselves. From the research paper findings, all these factors are significant since their path costs were above 0.05 , the theoretical established value.

\section{Summary And Conclusions}

The goal of this paper was to develop a model for the fingerprint technology. The researchers gave this model a name, BEACPT(Biometric- Based Authentication E-Card Payment Technology). This model was then evaluated using the questionnaire results obtained from the DTB customers and staff, Kisii Branch. This goal was successfully achieved. As shown above, accessibility, acceptability, robustness and distinctiveness, (ST1 to ST4 - with regression weights of 0.650 .700 .16 and 0.87 respectively) all from the signaling theory, were significant and hence crucial determinants for the adoption of E-card payment technology. Availability, individually perceived to influence the usefulness of this technology, was also significant with a regression 
weight of 1.74. On the other hand, construct ECPT3 loaded lower than the theoretical established value of 0.05 and was discarded.

The developed model added five observed constructs (availability, robustness, accessibility, acceptability and distinctiveness) that were measured using three latent constructs (BBA, $A V A L, S T$ and $E C P T$ ). These are the qualities of the system itself. From the research paper findings, all these factors were significant since their path costs were above 0.05 , the theoretical established value. This model can therefore be utilized in Diamond Trust Bank as a basis for the adoption of Biometric -Based authentication for E-Card Payment Technology. The possible improvement areas include developing a fingerprint sensor on mobile devices and on ATMs so that the proposed biometric-based authentication can be accomplished both in ATM transactions and on mobile banking transactions.

\section{References}

[1]. G. Diane, (2014), “What Is Fingerprint Authentication?”, Conjecture Corporation.

[2]. C. Jensen, (2009), "Identity and Privacy In Internet Age”, Springer Journals.

[3]. AdMonsters, (2013), "Putting Money into the Mobile Wallet"

[4]. B. Connelly (2011), "Signalling Theory: A review and Assesment", Journal Of Management.

[5]. F. Dainelli (2011), " Signalling theory and voluntary disclosure to the financial market", Evidence from the profitability indicators published in the annual report, Paper presented at the 34th EAA Annual Congress

[6]. Elizabeth et al., (2012), "Adoption of E-tax services in Uganda".

[7]. Martin S., (2014), "Instrument Reliability".

[8]. Mohammed Z.,(2013), "Mixed Method Research: Instruments, Validity, Reliability and Report Findings", Academy Publisher.

[9]. G. Ganzeboom, (2010), "LISREL: Interpreting the LISREL output"

[10]. A. Wallenburg (2012), "Dealing with supply chain risks: linking risk management practices and strategies to performance", international journal of physical distribution \& logistics management, 42(10).

[12]. D. Bridget (2011), "Legal Aspects of Occupational Therapy", John Wiley \& Sons

[13]. M. Gerhard (2010), "LISREL for Windows: Getting Started Guide".

[14]. Chuttur, M.Y. (2009), “Overview of the Technology Acceptance Model: Origins, Developments and Future Directions", Indiana University, USA, Sprouts. 